\title{
Morfologia e morfometria das papilas mamárias de búfalas ${ }^{1}$
}

\author{
Diogo A.S. Santos ${ }^{2}$, Rose E.G. Ricci ${ }^{3}$, Isaura M.M. Prado ${ }^{4}$, Ana F. Carvalho ${ }^{5}$, Pedro P. \\ Bombonato $^{3}$, Carlos E. Ambrósio ${ }^{3 *}$, Dulcinea G. Teixeira ${ }^{3}$, Tatiana C. Santos ${ }^{3}$, \\ Francisco J. Hernandes-Brazquez ${ }^{3}$, Daniele S. Martins ${ }^{3}$, Adriana C. Morini ${ }^{3}$, José R. \\ Kfoury $\mathrm{Jr}^{3}$ e Maria Angélica Miglino ${ }^{3}$
}

\begin{abstract}
Santos D.A.S., Ricci R.E.G., Prado I.M.M., Carvalho A.F., Bombonato P.P., Ambrósio C.E., Teixeira D.G., Santos T.C., H.-Brazquez FJ., Martins D.S., Morini A.C., Kfoury Jr J.R. \& Miglino M.A. 2007. [Morphology and morphometry of buffalo mammary papillae.] Morfologia e morfometria das papilas mamárias de búfalas. Pesquisa Veterinária Brasileira 27(3):95-102. Departamento de Cirurgia, Faculdade de Medicina Veterinária e Zootecnia, Universidade de São Paulo, Av. Prof. Dr. Orlando Marques de Paiva 87, Cidade Universitária, São Paulo, SP 05508270, Brazil. E-mail: ceambrosio@usp.br

Fifteen papillae from female water buffaloes and one bovine female were obtained in a slaughter house for this study, which consisted in morphologic and biometrical analyses, histology and histometric and mesoscopical analyses. The means were: right cranial papilla (RCP) 20.95g; right caudal papilla (RCaP) $21.49 \mathrm{~g}$; left cranial papilla (LCP) $23.52 \mathrm{~g}$; and left caudal papilla (LCaP) $21.35 \mathrm{~g}$. Papillary duct average length, numbers of folds and papillary cisterns length were, respectively: $0.67 / 5,5$ e $2.17 \mathrm{~cm}$ for RCP; $0.62 / 6.0$ e $2.26 \mathrm{~cm}$ for RCaP; and for the left antimere: RCP: $0.71 / 6.0$ e $2.26 \mathrm{~cm}$ and for RCaP: $0.74 / 5.7$ e $2.57 \mathrm{~cm}$. Pearson's analysis revealed negative correlation between body weight and mammary glandular weight. Sampling of proximal, middle and distal area was taken and fixed into a $10 \%$ formaldehyde solution, followed by mesoscopical investigation through 10,20 and $40 \mu$ m thickness cuts stained by Azan, F3BA Picrosirus and Weigert-Van Gieson techniques. Histological and morphometric analyses were applied on $5 \mu \mathrm{m}$ thick samples and showed that the muscular layer was disposed into two arrangements, internal circular and external longitudinal with a bi-stratified cuboidal epithelium. A well developed muscular layer were related to the middle portion revealing thickness of $22.90 \mathrm{~mm}$ with a great amount of connective tissue $(7.10 \mathrm{~mm})$.
\end{abstract}

INDEX TERMS: Buffaloes, mammary papilla, morphometry, morphology, Buballus bubalis.

RESUMO.- Para este estudo, quinze papilas de fêmeas de búfalos e uma de fêmea bovina foram obtidas no matadouro. Estudos macro e microscópico foram realizados por meio de diferentes técnicas: morfológica, histológica e análises, biométrica,

\footnotetext{
${ }^{1}$ Recebido em 5 de setembro de 2006.

Aceito para publicação em 28 de dezembro de 2006.

${ }^{2}$ Faculdade de Ciências Agrárias e Veterinárias, Universidade Estadual Paulista (Unesp), Via de Acesso Prof. Paulo Donato Castelane s/n, Jaboticabal, SP $14884-900$.

${ }^{3}$ Depto Cirurgia, FMVZ-USP, Av. Prof. Dr. Orlando Marques de Paiva 87, Cidade Universitária, São Paulo, SP 05508-270. *Autor para correspondência: ceambrosio@usp.br

${ }^{4}$ Universidade Estadual de Maringá, Av. Colombo 5790, Maringá, PR 87045000 .

${ }^{5}$ Centro Universitário da Fundação de Ensino Octávio Bastos (UNIFEOB), Rua General Osório 433. São João da Boa Vista, SP 13870-000.
}

histométrica e mesoscópica. As médias foram: papila cranial direita (PCD) 20,95g; papila caudal direita (PCaD) 21,49g; papila cranial esquerda (PCE) 23,52g; papila caudal esquerda (PCaE) $21,35 \mathrm{~g}$. O comprimento médio do ducto papilar, do número de pregas e do comprimento das cisternas papilares foi respectivamente: $0,67 / 5,5$ e $2,17 \mathrm{~cm}$ para a $P C D ; 0,62 / 6,0$ e $2,26 \mathrm{~cm}$ para a PCaD; e para o antímero esquerdo, PCD: 0,71/6,0 e 2,26cm e para PCaD: 0,74/5,7 e 2,57cm. A análise de Pearson revelou uma correlação negativa entre o peso do corpo e o peso da glândula mamária. Foi feita a amostragem das três áreas proximal, média e distal e estas foram fixadas em formaldeído a $10 \%$, seguindo-se a investigação mesoscópica em amostras de espessuras de 10, 20 e 40 $\mu \mathrm{m}$ coradas pelas técnicas Azan, F3BA Picrosirus e Weigert - Van Gieson. As análises histológicas e morfométricas foram feitas em amostras de $5 \mu \mathrm{m}$ de espessura o que mostrou que a camada muscular estava disposta em dois 
arranjos, interna circular e externa longitudinal com epitélio cubóide bi-estratificado. A camada muscular bem desenvolvida estava relacionada com a porção média revelando uma espessura de $22,90 \mathrm{~mm}$ com uma grande quantidade de tecido conectivo $(7,10 \mathrm{~mm})$.

TERMOS DE INDEXAÇÃO: Búfalos, papila mamária, morfometria, morfologia, Buballus bubalis.

\section{INTRODUÇÃO}

Devido aos atributos fisiológicos inerentes à espécie, os bufalinos apresentam uma marcante superioridade frente aos bovinos. Este fator prevalece, por ser a espécie provida de rusticidade, precocidade e fertilidade, além de se adaptar facilmente aos diferentes ambientes.

Desde a introdução da espécie no país, há pouco mais de 100 anos, sua presença se faz notada em praticamente todos os estados, tendo apresentado na última década uma taxa de crescimento seis vezes superior à taxa de crescimento mundial $(2 \%)$, fato que evidência a viabilidade de sua criação (Vale et al.1999).

O aproveitamento do leite de búfalas no Brasil tem apresentado crescente aumento, tanto pelo fato destes animais apresentarem ótimos índices de conversão de matéria seca em leite, como pelos elevados teores de gordura e sólidos totais que ele possui, propiciando alto rendimento na fabricação de queijos finos (Tonhati et al. 1999). Em muitas áreas rurais dos países em desenvolvimento, o leite de búfala é responsável pela fixação do homem no campo, proporcionando trabalho e incrementando a agricultura familiar.

Do ponto de vista reprodutivo, os bufalinos assemelhamse aos bovinos, mas presentam características inerentes à espécie, tais como: tamanho e peso dos ovários, coloração e inserção do corpo lúteo, cérvix mais tortuosa e com maior número de anéis cervicais (Miglino 1999).

Sabe-se que na espécie bovina, a maioria das infecções das glândulas mamárias ocorre por via ascendente, comprometendo o seu parênquima. Portanto, a boa oclusão do óstio papilar funciona como barreira mecânica contra infecções. Além disso, o estresse da ordenha afeta a higidez da glândula, podendo levar a inflamações e a formação de tecido cicatricial, o qual projetando-se para o lumen poderá obstruir, parcial ou totalmente o fluxo lácteo (Arnold \& Weber 1957, Steere et al. 1960, Schalm et al. 1971b).

Apesar da grande expansão da bubalinocultura em nosso país, poucos são os estudos disponíveis referentes à glândula mamária e suas patologias concernentes à espécie (Costa 1999), sendo que a sua morfologia confunde-se com a dos bovinos, pois os tratados anatômicos não mencionam informações específicas. Assim, no presente artigo estudou-se a morfologia da papila mamária de búfalas, abordando os aspectos morfológicos e morfométricos, buscando contribuir para o entendimento da fisiopatologia da papila mamária nesta espécie, fornecendo subsídios para escolha e esclarecimento do manejo e da terapêutica adequados, uma vez que muitas técnicas descritas para o tratamento das infecções mamárias em bovinos são extrapoladas para bufalinos.

\section{MATERIAL E MÉTODOS}

Foram utilizadas papilas mamárias de 15 fêmeas de búfalas da raça Murrah e de uma fêmea bovina mestiça, no período não-lactante, provenientes de frigoríficos dos Estados do Maranhão, São Paulo e Paraná. O material foi aleatoriamente destinado a diversas técnicas, totalizando 64 papilas mamárias analisadas.

Análise macroscópica. Em cada um dos 16 úberes as papilas mamárias foram identificadas quanto à localização e posicionamento: papila cranial direita (PCD); papila cranial esquerda (PCE); papila caudal direita $(\mathrm{PCaD})$ e papila caudal esquerda $(\mathrm{PCaE})$. Após realização de documentação fotográfica (microscópio estereoscópico Olympus SZ40), o material foi fixado em formol a $10 \%$ em solução tampão fosfato $\mathrm{pH}$ 7,7-0,1M sendo que quatro papilas de búfala fixadas em Paraformaldeído a $4 \%$ em solução tampão fosfato $\mathrm{pH} 7,0-0,1 \mathrm{M}$ para análise mesoscópica.

Análise biométrica macroscópica. Os úberes de 10 búfalas foram seccionados ao longo do sulco intermamário e cada antímero foi pesado em balança digital cujos pesos foram correlacionados com o peso corporal do animal (Quadro 1). Quatro búfalas tiveram suas papilas mensuradas para obtenção de correlação de tamanho entre papilas (Quadro 2).

Análise mesoscópica. Quatro papilas mamárias de búfalas foram mergulhadas em ácido nítrico a $30 \%$, onde permaneceram por um período de 6 a 48 horas. Após este período, iniciou-se a dissecção dos feixes de fibras musculares, sob um estereoscópio (Olympus SZ40), com auxílio de uma agulha, pinça e tesoura. Parte do material após a dissecção foi mergulhada em solução de Van-Gienson, por 24 horas, para posterior estudo, segundo citado por Didio, (1952). Completada a dissecção o material foi processado rotineiramente em parafina (Behmer et al. 1976) e os blocos foram cortados com espessura de 10,20 e $40 \mu \mathrm{m}$ e corados alternadamente, pelas técnicas de Azan, Weigert-Van Gieson (Behmer et al. 1976) e picrosírus F3BA (Junqueira et al. 1979). Os cortes foram analisados em um microscópio Olympus CBB, com e sem filtro de luz polarizada e em estereomicroscópio Olympus SZ40.

Análise microscópica. Fragmentos das três porções papilares (proximal, média e distal) das papilas bufalinas e das bovinas foram pós-fixados em solução de Bouin durante 24 horas, totalizando 64 papilas analisadas. Os fragmentos foram processados rotineiramente para inclusão em Histosec ${ }^{\circledR}$ (Merck, lot K91225309) segundo Behmer et al. (1976). A maioria das papilas foi incluída transversalmente para análise de suas camadas histológicas, somente 4 papilas foram incluídas de modo longitudinal respeitando-se as porções proximal, média e distal assim como nas demais. Destes blocos foram feitos cortes seqüenciais com $5 \mu \mathrm{m}$ de espessura (Micrótomo Leica 2165). Os cortes receberam as colorações de HematoxilinaEosina de Harris, Tricrômico de Masson e Weigert-Van Gieson (Behmer et al. 1976). Após análise, os cortes foram documentados em um fotomicroscópio modelo Eclipse Nikon E-400.

Análise histométrica. Cortes seqüenciais de $5 \mu \mathrm{m}$ de uma amostragem de 16 papilas bufalinas foram feitos seguindo-se o seguinte critério: a cada 10 cortes feitos 9 eram desprezados e um coletado em lâmina, perfazendo um total de 10 cortes coletados por papila e 30 campos de observação por corte, desde as camadas teciduais constituintes da porção média do conduto papilar, do lume em direção à periferia os quais foram mensurados em um sistema analisador de imagens da Kontron Elektronik (Video Plan), acoplado a um microscópio binocular, ambos da Carl Zeiss.

Análise Estatística. Os resultados foram submetidos ao teste de correlação de Pearson, respeitando a localização de cada papila. Os valores foram classificados como: baixa correlação, $r=0-0,49$; média correlação, $r=0,5-0,75$; e alta correlação, $r=0,76$ a 1 . 


\section{RESULTADOS}

\section{Resultados macroscópicos morfológicos e biométricos}

0 peso corporal das quinze fêmeas bufalinas variou de 302 a $462 \mathrm{~kg}(389,60 \pm 53,74 \mathrm{~kg})$. O peso do úbere (com suas respectivas glândulas) oscilou entre 1,80 a $10,33 \mathrm{~kg}(3,32 \pm 2,55 \mathrm{~kg})$, representando $0,84 \pm 0,56 \%$ do peso corpóreo do animal (Quadro 1 ).

Quadro 1. Peso corporal e dos antímeros direito (AD) e esquerdo (AE) da glândula mamária (kg) e porcentagem da glândula em relação ao peso corporal (G/PC) de fêmeas bufalinas. São Paulo, 2003

\begin{tabular}{cccccc}
\hline Búfalas & $\begin{array}{c}\text { Peso cor- } \\
\text { poral }(\mathrm{kg})\end{array}$ & \multicolumn{2}{c}{ Peso da glândula mamária $(\mathrm{kg})$} & $\mathrm{G} / \mathrm{PC}$ \\
\cline { 2 - 4 } & Peso $\mathrm{AD}^{\mathrm{a}}$ & ${\text { Peso } \mathrm{AE}^{\mathrm{b}}}^{\mathrm{n}}$ & Total & \\
\hline 1 & 302 & 2,00 & 1,85 & 3,85 & 1,27 \\
2 & 380 & 1,04 & 1,05 & 2,10 & 0,55 \\
3 & 462 & 1,44 & 1,98 & 3,43 & 0,74 \\
4 & 360 & 1,05 & 1,15 & 2,20 & 0,61 \\
5 & 380 & 1,20 & 1,15 & 2,35 & 0,61 \\
6 & 320 & 0,92 & 0,96 & 1,88 & 0,59 \\
7 & 432 & 0,85 & 0,95 & 1,80 & 0,41 \\
8 & 430 & 1,33 & 1,51 & 2,85 & 0,66 \\
9 & 380 & 1,29 & 1,13 & 2,42 & 0,63 \\
10 & 450 & 5,41 & 4,92 & 10,33 & 2,29 \\
Média & 389,6 & 1,65 & 1,66 & 3,32 & 0,84 \\
\end{tabular}

aAntímero direito, bantímero esquerdo.

Quadro 2. Correlação de Pearson entre quatro matrizes, referentes a dados das papilas mamárias de búfalas. São Paulo, 2003

\begin{tabular}{|c|c|c|c|c|c|c|}
\hline COMPa $^{\mathrm{a}}$ & $\mathrm{DP}^{\mathrm{b}}$ & $\mathrm{DM}^{\mathrm{c}}$ & $\mathrm{DD}^{\mathrm{d}}$ & $\mathrm{PT}^{\mathrm{e}}$ & $\mathrm{Cl}^{\mathrm{f}}$ & $\mathrm{CO}^{\mathrm{g}}$ \\
\hline \multicolumn{7}{|c|}{ Matriz de correlação - PcaD (Papila caudal direita) } \\
\hline $\mathrm{DP}^{\mathrm{b}}$ & $-0,4887$ & & & & & \\
\hline $\mathrm{DM}^{\mathrm{c}}$ & 0,2612 & 0,5431 & & & & \\
\hline $\mathrm{DD}^{\mathrm{d}}$ & 0,3955 & 0,198 & 0,5639 & & & \\
\hline $\mathrm{PT}^{\mathrm{e}}$ & 0,4758 & $-0,2727$ & 0,3164 & 0,125 & & \\
\hline $\mathrm{Cl}^{\mathrm{f}}$ & 0,0535 & 0,515 & 0,559 & 0,7202 & $-0,2977$ & \\
\hline $\mathrm{CO}^{\mathrm{g}}$ & $-0,3297$ & 0,4798 & 0,2968 & 0,5577 & $-0,6026$ & 0,8122 \\
\hline \multicolumn{7}{|c|}{ Matriz de correlação - PcaE (Papila caudal esquerda) } \\
\hline DP & $-0,2362$ & & & & & \\
\hline DM & 0,468 & 0,5603 & & & & \\
\hline DD & $-0,0413$ & 0,3144 & 0,5129 & & & \\
\hline PT & 0,5744 & 0,4163 & 0,6884 & 0,0448 & & \\
\hline $\mathrm{CI}$ & $-0,1711$ & 0,1647 & $-0,0524$ & 0,4597 & $-0,394$ & \\
\hline $\mathrm{CO}$ & $-0,3721$ & 0,1997 & $-0,3313$ & 0,3741 & $-0,5857$ & 0,7404 \\
\hline \multicolumn{7}{|c|}{ Matriz de correlação - PCD (Papila cranial direita) } \\
\hline DP & 0,2336 & & & & & \\
\hline DM & 0,7816 & 0,6154 & & & & \\
\hline DD & 0,2996 & 0,595 & 0,534 & & & \\
\hline PT & 0,9224 & 0,2942 & 0,7987 & 0,0942 & & \\
\hline $\mathrm{CI}$ & $-0,1211$ & 0,5784 & 0,055 & 0,7942 & $-0,3227$ & \\
\hline $\mathrm{CO}$ & 0,2704 & 0,2479 & 0,2801 & 0,6364 & 0,06 & 0,5545 \\
\hline \multicolumn{7}{|c|}{ Matriz de correlação - PCE (Papila cranial esquerda) } \\
\hline DP & 0,7437 & & & & & \\
\hline DM & 0,8882 & 0,8478 & & & & \\
\hline DD & 0,5004 & 0,7179 & 0,6907 & & & \\
\hline PT & 0,9377 & 0,7285 & 0,9374 & 0,5553 & & \\
\hline $\mathrm{CI}$ & $-0,1034$ & 0,5201 & 0,137 & 0,6357 & $-0,1153$ & \\
\hline $\mathrm{CO}$ & $-0,1765$ & 0,2092 & $-0,0112$ & 0,3122 & $-0,137$ & 0,6452 \\
\hline
\end{tabular}

a Comprimento, b diâmetro proximal, ${ }^{\mathrm{c}}$ diâmetro medial, ${ }^{\mathrm{d}}$ diâmetro distal,

e peso do teto, ${ }^{\mathrm{f}}$ cisterna, ${ }^{\mathrm{g}}$ conduto.
Na análise de correlação o peso total da glândula mamária e o peso dos antímeros apresentaram correlação alta e positiva entre os pesos dos antímeros direito e esquerdo, e entre o peso de cada antímero e o peso total da glândula. A comparação do peso de cada antímero e peso total da glândula com o peso corporal obtiveram correlação baixa e positiva.

As papilas mamárias caudais mostraram correlações alta e positiva entre cisterna $\mathrm{x}$ conduto papilar e média e positiva entre o peso x comprimento e diâmetro distal $\mathrm{x}$ cisterna. Nas papilas craniais observaram-se correlações positivas e altas para: comprimento $\mathrm{x}$ peso do teto; comprimento $\mathrm{x}$ diâmetro da porção média; diâmetro da porção média $\mathrm{x}$ peso do teto, $\mathrm{e}$ ainda, correlação positiva e média entre: cisterna $\mathrm{x}$ conduto; diâmetro proximal $\mathrm{x}$ cisterna e diâmetro distal $\mathrm{x}$ cisterna. Correlação negativa e baixa foi encontrada entre o comprimento e a cisterna em todas as papilas mamárias analisadas (Quadro 2).

\section{Quadro 3. Valores teciduais médios $(\mathrm{mm})$, mensurados no conduto papilar, do lume para a periferia, das papilas mamárias de fêmea bufalina ${ }^{a}$}

\begin{tabular}{|c|c|c|c|c|c|}
\hline Parâmetros analisados & PCD & PCE & PcaD & $\mathrm{PcaE}$ & Média \\
\hline Tecido epitelial (Ducto papilar & r) 299,47 & 288,79 & 253,88 & 268,68 & 277,7 \\
\hline Tecido conjuntivo (frouxo) & 159,39 & 88,52 & 140,54 & 223,12 & 152,89 \\
\hline $\begin{array}{l}\text { Tecido muscular (Camada } \\
\text { muscular circular e lon- } \\
\text { gitudinal) }\end{array}$ & 26419,79 & 20244,43 & 17936,86 & 27073,02 & 22981,53 \\
\hline $\begin{array}{l}\text { Tecido conjuntivo (denso } \\
\text { não modelado) }\end{array}$ & 6753 & 716 & 460 & 9877,78 & 9,37 \\
\hline Tecido conjuntivo (frouxo) & & & 17 & & 202,43 \\
\hline Tecido epitelial (Epiderme) & 397,28 & 450,15 & 259,8 & 174,09 & 320,33 \\
\hline
\end{tabular}

aCada valor representa a média de 30 observações por tecido

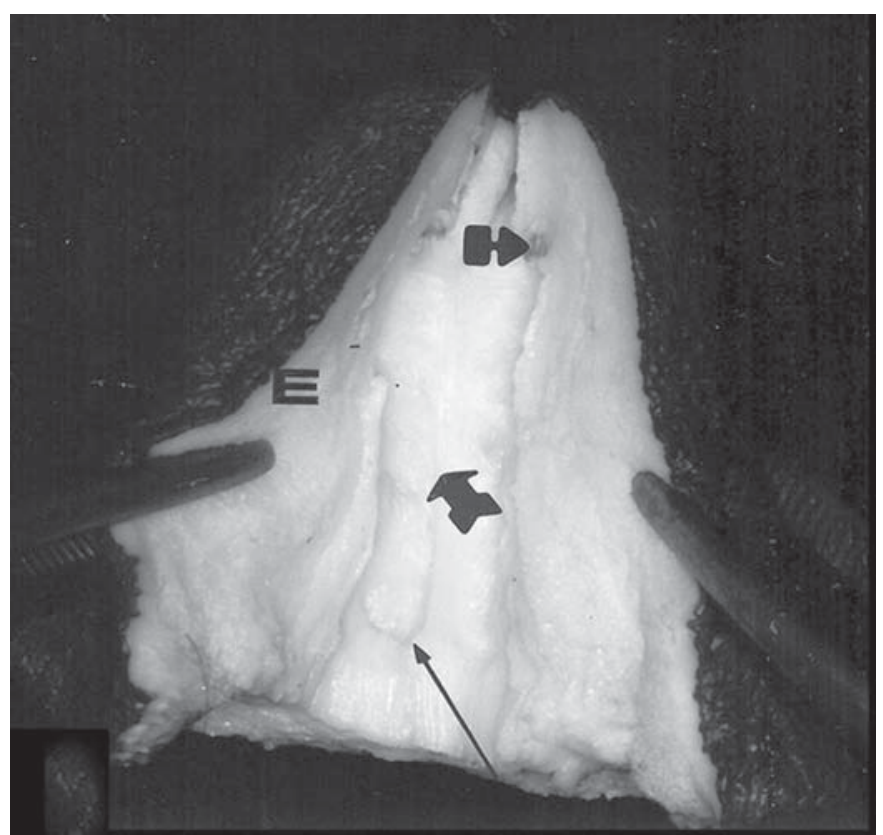

Fig.1. Fotografia evidenciando o corte sagital da papila mamária de fêmea bufalina. Epiderme e derme (E); Seio lactífero (seta do meio); "Roseta de Fürstenberg" (seta superior). Pregas longitudinais (seta fina) são evidentes. 
A análise das medidas dos diâmetros proximal, médio e distal das papilas mamárias denotou o predomínio do formato de "garrafa" (Quadro 3) (Fig.1) e em duas fêmeas bufalinas notou-se a presença de papilas mamárias acessórias, localizadas caudalmente às principais, uma no antímero direito e outra no esquerdo.

A mucosa papilar apresentou, predominantemente, pregas longitudinais e algumas transversais. Este número variou de 5 a 6 pregas.

\section{Resultados da análise mesoscópica}

Com relação à análise mesoscópica da organização da túnica muscular, a observação dos cortes espessos mostrou feixes de fibras musculares com disposição circular (internamente), e feixes com disposição longitudinal (externos). Na região da "roseta de Fürstenberg" feixes de fibras musculares com disposição circular, associados a grande quantidade de tecido conjuntivo, acompanhavam todo o diâmetro da papila. Estes feixes estavam organizados em duas ou três camadas sobrepostas da luz da papila em direção ao seu epitélio, separadas por tecido conjuntivo (Fig.1). O componente colágeno do tecido conjuntivo foi bem evidenciado pela coloração picrosírius F3BA. Na região da "roseta de Fürstenberg", as camadas de feixes de fibras musculares estavam envolvidas por feixes de fibras colágenas corados em vermelho e amarelo (Fig.2). Estes feixes colágenos, aparentemente, tomavam também disposição circular para separar uma camada muscular de outra. Na camada mais externa observou-se um acúmulo de feixes de fibras colágenas. Nesta região, o estrato longitudinal resumia-se em alguns feixes isolados com disposição longitudinal. Em direção proximal, alguns feixes da camada mais externa do estrato circular desprendiam-se tomando disposição oblíqua a longitudinal. Isto se repetiu gradualmente em cada uma das camadas, de modo que na porção média da papila as camadas eram dificilmente identificadas, predominando a ocorrência de feixes oblíquos e longitudinais, dispostos de modo disperso e aleatório por toda a espessura da parede da papila mamária (Fig.3).
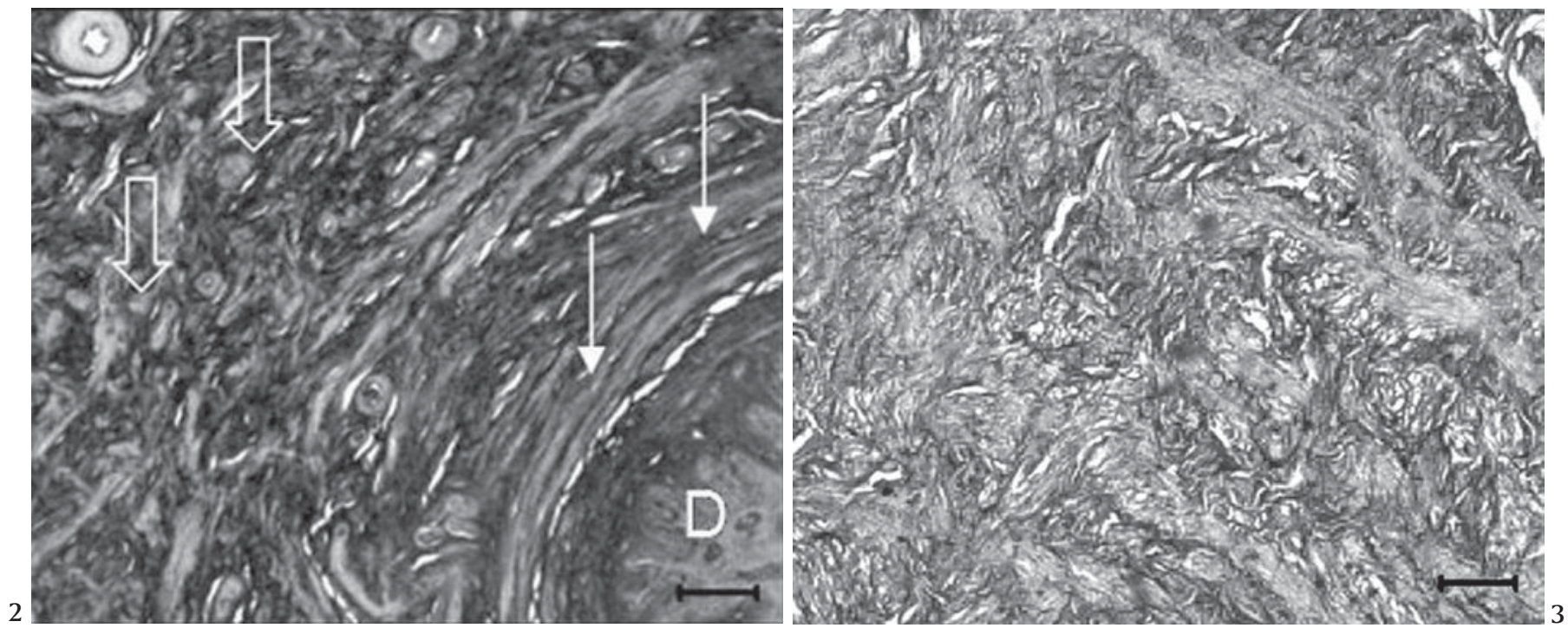

Fig.2. Porção distal da papila mamária de fêmea bufalina, na região da roseta de Fürstenberg, em corte transversal de $20 \mu \mathrm{m}$, evidenciando a disposição circular dos feixes de fibras musculares (setas cheias), associados a feixes de fibras colágenas (setas vazias), acompanhando o diâmetro do ducto papilar (D). Note a organização dos feixes em camadas sobrepostas, separadas por tecido conjuntivo e vasos sangüíneos. Azan, Picrosírius $\mathrm{F}_{3} \mathrm{BA}$. Bar$\mathrm{ra}=100 \mu \mathrm{m}$.

Fig.3. Corte transversal de $20 \mu \mathrm{m}$, evidenciando a disposição aleatória dos feixes de fibras musculares (claros) na sua porção média. Feixes de fibras colágenas (cinzas); fibras elásticas (preto). Weigert - Van Gieson. Barra $=400 \mu \mathrm{m}$.

Fig.4. Região média da papila mamária evidenciando as camadas do epitélio: Camada basal (A); Camada espinhosa (B); Camada granulosa (C); Camada córnea (D); Camada superficial do epitélio com células pavimentosas (E). HE. Barra $=100 \mu \mathrm{m}$.

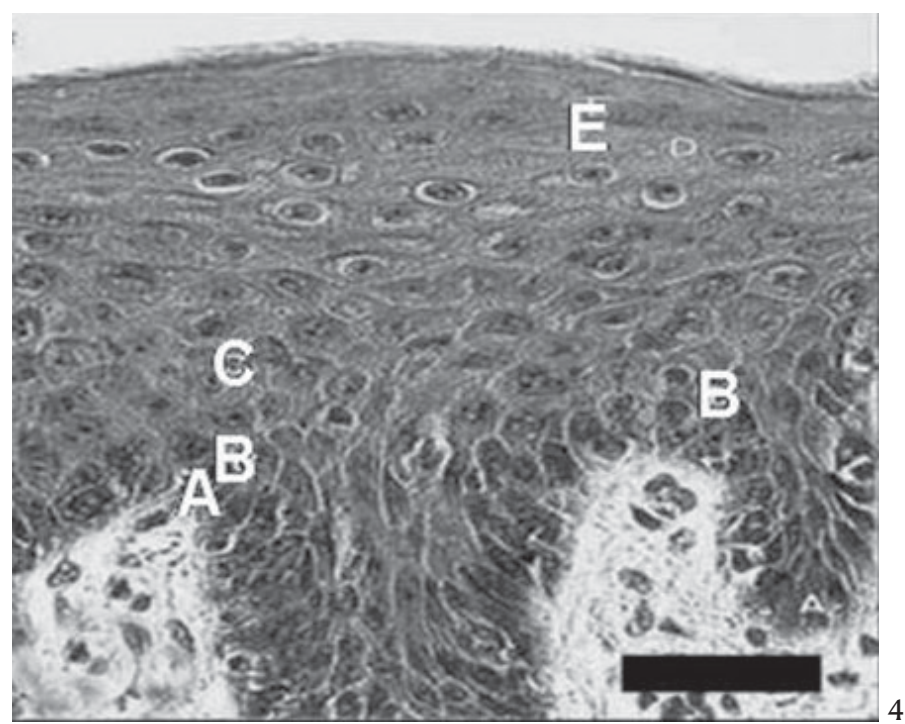




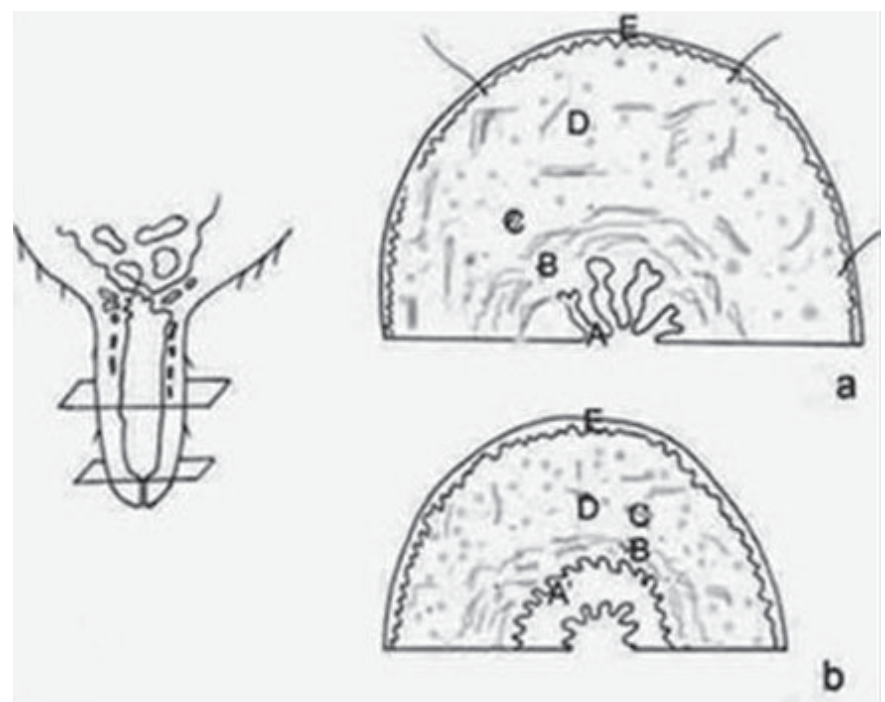

Fig. 5. Desenhos esquemáticos representativos de secções transversais da papila mamária da búfala. (a) Porção média, (b) Porção distal. (A) Localização do epitélio biestratificado cúbico, (A') Localização do epitélio estratificado com larga camada de queratina, (B) Localização da camada de musculatura lisa (corte transversal), (C) Localização da camada de musculatura lisa na disposição longitudinal, (D) Localização do tecido conjuntivo frouxo, (E) Localização do epitélio pavimentoso estratificado queratinizado.

Os feixes de fibras musculares encontravam-se associados ao tecido conjuntivo, com fibras colágenos e elásticas. Os feixes de fibras elásticas não mostraram um arranjo específico, mas foi possível evidenciar muitos feixes com disposição longitudinal. Os feixes de fibras musculares tinham um arranjo circular bem estabelecido. Estes pareciam estar envolvidos por numerosos feixes de fibras elásticas.

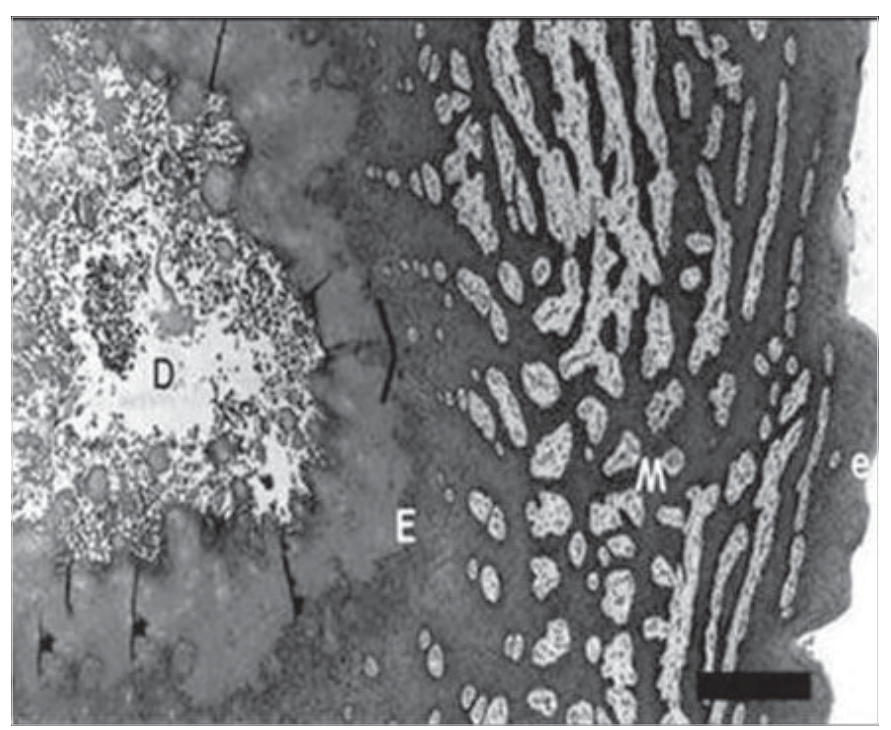

Fig.6. Óstio papilar de búfala, mostrando a arquitetura do óstio papilar; epitélio pavimentoso estratificado queratinizado (E); porção média $(\mathrm{M})$ com tecido conjuntivo e epitélio; epitélio epidérmico (E); ducto papilar (D). HE. Barra $=150 \mu$.

\section{Resultados histológicos}

Histologicamente foram identificados os seguintes estratos (da epiderme em direção ao conduto papilar): epitélio de revestimento externo da papila, tecido conjuntivo, camada muscular e mucosa papilar. $\mathrm{O}$ epitélio externo da papila mamária apresentou-se pavimentoso estratificado queratinizado, com cinco camadas distintas: germinativa, espinhosa, granulosa, lúcida e córnea (Fig.4). Na porção média e proximal da papila mamária evidenciou-se a presença de glândulas sudoríparas e glândulas sebáceas associadas a folículos pilosos relacionados ao epitélio externo e interno do conduto papilar. O epitélio da mucosa papilar mostrou-se, em sua maior extensão, como biestratificado cúbico, com raras regiões de epitélio colunar simples apresentando células basais. $\mathrm{O}$ óstio papilar era revestido pelo mesmo epitélio de revestimento externo da papila. Este tipo de epitélio revestia o conduto papilar, modificando-se para bi-estratificado cúbico a partir da roseta de Fürstenberg em direção proximal. Na altura da roseta de Fürstenberg formavam-se, lateralmente, dois divertículos recobertos pelo mesmo epitélio.

Uma extensa camada de tecido conjuntivo denso nãomodelado estava presente em todas as porções da papila entremeada por feixes de fibras musculares como ilustra o esquema da Fig.5. Estas fibras musculares estavam organizadas em duas camadas: uma mais externa ao conduto papilar, com disposição longitudinal ao eixo maior da papila, composto por feixes esparsos e desorganizados; e outra, mais interna e próxima ao conduto papilar, mais organizada e desenvolvida, com disposição circular (Fig.5). Em direção a porção distal do óstio papilar a quantidade de fibras musculares diminuía gradativamente até sua abertura. A observação das papilas mamárias bovinas com intuito comparativo evidenciou as mesmas características histológicas gerais das bufalinas. Contudo, a camada muscular na papila mamária bovina era mais organizada e suas camadas musculares, longitudinal e circular, bem mais definidas que nas papilas de fêmeas bufalinas (Fig.6).

\section{Resultados da análise histométrica}

Os dados referentes à histometria das camadas que compõe a porção média da papila mostram que as camadas musculares da túnica muscular e a camada constituída por tecido conjuntivo denso são as mais desenvolvidas na parede da papila mamária. O tecido epitelial de revestimento do conduto papilar apresentou média de $277,70 \mu \mathrm{m}$ de espessura e seu tecido conjuntivo frouxo adjacente $152,89 \mu \mathrm{m}$; as camadas musculares, longitudinal e circular somaram em média $22.918,53 \mu \mathrm{m}$. O epitélio de revestimento externo da pila apresentou média de $320,33 \mu \mathrm{m}$ sendo, portanto mais espesso do que o do conduto papilar, e seus tecidos conjuntivos adjacentes somaram $202,43 \mu \mathrm{m}$ (tecido conjuntivo frouxo) e $7.099,37 \mu \mathrm{m}$ (tecido conjuntivo denso não modelado). (Quadro 3)

\section{DISCUSSÃO E CONCLUSÃO}

É fato que na espécie bovina, a maioria das infecções das glândulas mamárias ocorre por via ascendente, comprometendo 
o seu parênquima. Portanto, a boa oclusão do óstio papilar funciona como barreira mecânica contra infecções. Além disso, o estresse da ordenha afeta a higidez da glândula, podendo levar a inflamações e a formação de tecido cicatricial, o qual projetando-se para o lume poderá obstruir, parcial ou totalmente o fluxo lácteo (Arnold \& Weber 1957, Steere et al. 1960, Schalm et al. 1971b). Esta abordagem morfológica nos levou a desenvolver este trabalho, buscando alguma correlação entre a morfologia dos bufalinos e a pouca incidência de infecções mamárias nesta espécie. Assim esperamos contribuir com informações específicas para criação de maquinaria adequada para ordenha bufalina.

Assim como nos bovinos, macroscopicamente notou-se a presença de papilas mamárias acessórias em dois animais. Este padrão era semelhante ao descrito para bovinos (Schalm et al. 1971, Nickel et al. 1981) e em bovinos e bubalinos (Tomar \& Verma 1974, Verma et al. 1984, Schimit et al. 1994 ). Portanto, este fato deve ser levado em consideração quando se procede à ordenha em bufalinos, sendo, portanto necessário identificar nos animais que serão ordenhados se há somente hipertelia simples ou hipertelia com hipermasia.

As características do epitélio da papila mamária, bem como a ocorrência de pêlos e glândulas sudoríparas e sebáceas, corresponderam ao descrito para as espécies bovina (Bacha Jr \& Wood 1990) e bufalina (Uppal et al. 1995). Porém, não encontramos referência sobre a presença de glândulas apócrinas ou holócrinas voltadas para o epitélio do conduto papilar, como observado em nosso material nas porções proximal e média. A presença destas glândulas no estrato germinativo e espinhoso do conduto papilar tem sido atribuída à produção do selante, que se refaz a cada ordenha (Nicherson, 1987).

O epitélio de revestimento do conduto papilar mostrouse semelhante aos relatados para a mesma espécie e para a bovina (Arnold \& Weber 1957). O arranjo especial das diferentes camadas celulares que compõem este epitélio está associado a sua disposição perpendicular ao eixo principal do conduto papilar, produzindo as pregas longitudinais, as quais auxiliam na obliteração do conduto quando o esfíncter se contrai. Segundo Schalm et al. (1971b) as projeções das camadas epiteliais e subepitelial em direção ao conduto são mais evidentes na região média e proximal deste.

O epitélio da mucosa do seio papilar mostrou-se, na sua maior extensão, como biestratificado cúbico, com poucas áreas de epitélio colunar, conforme indicado para esta espécie (Uppal et al. 1995), diferindo do epitélio colunar biestratificado relatado em bovinos (Nicherson \& Pankey 1983).

Os feixes de fibras musculares das papilas mamárias das fêmeas bufalinas e da bovina apresentavam-se organizados em um estrato circular, mais próximo ao conduto, e um longitudinal, mais externamente. $O$ estrato circular era bem delineado em ambas as espécies estudadas, contudo os feixes com disposição longitudinal, na espécie bufalina, eram dispersos e descontínuos. Na espécie bovina, estes últimos feixes mostraram-se mais definidos, em acordo com o descrito para a espécie (Pounden \& Grossman 1950).

As análises de cortes espessos permitiram identificar fei- xes de fibras musculares dispersos por toda espessura da parede papilar, sem um arranjo específico, e feixes isolados com disposição oblíqua e longitudinal, sugerindo um arranjo espiralado nas porções proximal e média da papila mamária. Apesar de não identificar na literatura consultada a descrição dos feixes musculares ao longo de todo o comprimento da papila mamária, na espécie bovina ou na bufalina, o arranjo nestas porções é indicativo de uma ação de extensão e retração da papila, o que é condizente com o habitat desta espécie e de uma mecânica particular para a liberação do leite.

Na região do duto papilar (roseta de Fürstenberg), o estrato circular era bem definido e predominante, com feixes dispostos em duas ou três camadas separados por feixes de fibras colágenas e envolvidos por fibras elásticas. A disposição circular destas fibras a este nível tem sido referida como tendo função de esfíncter em bovinos (Bernabé \& Peeters 1980). De fato a disposição circular de feixes musculares em estruturas tubulares leva à dedução de uma ação esfinctérica, quando da contração muscular. Contudo, nossos resultados são indicativos que tais feixes não são os únicos responsáveis pela atividade da papila. Segundo esses autores o componente vascular da papila, proeminente na sua porção média e distal, certamente contribui para a ação esfinctérica e de ejeção do leite. Além disso, o tecido conjuntivo associado deve fazer parte integrante da atividade motora da papila. A abertura ou fechamento do duto estaria na dependência da funcionalidade dos elementos que compõem o sistema.

Assim, os feixes musculares circulares formariam seu "esqueleto". Por outro lado os espessos feixes de fibras colágenas (considerados como fibras de resistência) envolveriam este esqueleto protegendo a estrutura contra tensões. As fibras delgadas exerceriam uma função estrutural, estando relacionados com a expansibilidade do órgão (Junqueira \& Carneiro 1999).

Por fim, as fibras elásticas, envolvendo os feixes musculares, contribuiriam para a interligação de todas as estruturas e teria, em condições normais, função de fechamento passivo. Os valores para o comprimento papilar assemelharam-se aos obtidos em búfalos na Índia (Akhtar \& Thakuria 1999), considerando que os relatos foram realizados em fêmeas em lactação. Por outro lado, nossos valores foram inferiores aos descritos em bovinos (Nickel et al. 1981, Dyce et al.1990). O valor médio do comprimento do conduto papilar foi inferior ao descrito em bovinos (Schalm et al. 1971b) e bufalinos (Uppal et al. 1995). O aumento do comprimento papilar não acompanhado pelo aumento do comprimento da cisterna pode caracterizar uma maior espessura da parede papilar.

Identificamos, em $100 \%$ dos casos, papilas em forma de garrafa, discordando com outros relatos no búfalo (Rao \& Murthy 1991, Aktar \& Thakuria 1999). Em bovinos (Rathore \& Sheldrake. 1977, Seykora \& McDaniel 1985) o formato cilíndrico e o de garrafa têm sido referidos como mais propensos às lesões do óstio, como resultado de ordenha incompleta.

Os divertículos laterais na região de transição do epitélio, na junção entre o seio papilar e conduto, ao nível da roseta 
de Fürstenberg, foram também indicados (Uppal et al. 1995) para esta espécie, e Banks (1992) fez referência a esta estrutura na espécie bovina, sendo considerada como uma região que poderia atuar como reservatório microbiano, favorecendo a infecção ascendente. Outros autores admitem que o contato mais íntimo da bactéria, ou de sua toxina, com a superfície deste epitélio (biestratificado) poderia favorecer uma melhor resposta das células de defesa (Nicherson 1987), ainda que a proteção contra infeç̧ões seja mais influenciada pelo aumento do fluxo sanguíneo na região, pelo estímulo da ordenha e por uma maior atividade mequadroólica do epitélio estratificado, em repor as perdas de queratina ocorridas (Jankus \& Baumann 1986).

Poderíamos com isso inferir que as alterações sofridas pela papila mamária durante o processo de ordenha (manual/mecânica) possibilitariam o "deslizamento" dos feixes musculares, que, devido ao seu arranjo espacial, manteriam as devidas relações topográficas.

Esta complexa "unidade mioconjuntiva" pode ter uma função compensatória, em detrimento ao menor comprimento do conduto papilar da espécie, quando comparado aos bovinos, impedindo assim a progressão do agente patógeno para o interior da cisterna papilar.

Por outro lado, a disposição específica e a íntima relação observada entre o tecido muscular e o conjuntivo sugerem uma maior rigidez da papila mamária de búfalas e que pode ser considerado benéfico, favorecendo a plastia papilar, permitindo uma melhor fixação dos fios de sutura. Ao fazermos uma analogia com a espécie bovina, podemos supor que a contração destes músculos no período pré-ordenha, após os estímulos físicos térmicos e mecânicos, seriam mais eficientes.

A ordenha mecânica é uma realidade crescente em nosso país e tem um papel importante na higidez da papila mamária, sendo fundamental o conhecimento do funcionamento correto de todas as partes do sistema, tanto de suas partes (como teteiras, pulsador e nível de vácuo), como de seu uso adequado. As fêmeas bufalinas são consideradas, por técnicos e criadores, como animais de "difícil ordenha", assim, inadvertidamente recomenda-se o aumento do nível do vácuo, objetivando aumentar a velocidade de ordenha. Schalm et al. (1971) relatam que a compressão constante e repetitiva na região distal do conduto papilar, aplicada no processo de ordenha, pode levar a injúrias e mudanças no epitélio da região, o que é, particularmente, verdadeiro para papilas menores. Citam ainda que em bovinos, fatores que induzam à liberação de catecolaminas (como dor e estresse) podem reduzir a liberação do leite por inibir a ação da ocitocina. Provavelmente, o aumento no nível da pressão tenha um efeito maior sobre a espécie bufalina, na medida em que aumentamos o número de ordenhas diárias, considerando que estes animais mantêm algumas características atávicas, sendo, portanto mais sujeitos ao estresse da ordenha.

Os tratamentos de mastite prescritos para a espécie bovina são os mesmos aplicados à bufalina. O diâmetro das cânulas plásticas de infusão, usadas para tratamento intramamário, tem sido referido como superior ao diâmetro do conduto papilar de bovinos, sendo que a inserção total da cânula provoca a dilatação temporária do conduto, com introdução da queratina para o interior da cisterna, induzindo a novas infecções (Nicherson 1987). A eficiência dos métodos corretivos e/ou profiláticos das glândulas mamárias (e de suas papilas) está na dependência do conhecimento pleno da anatomia da região e da função das estruturas que a compõem Pouden \& Grossman (1950). Considerando que o duto papilar de bufalinos tem diâmetro menor do que o de bovinos, podemos inferir que a introdução total da cânula nessa espécie poderia causar danos ainda mais graves do que os descritos para a espécie bovina.

Em bovinos, (Schalm et al. 1971b) a higienização e secagem das papilas associadas aos sons característicos do ambiente de ordenha funcionam como estímulo para a velocidade de liberação e produção do leite, bem como para a liberação do leite residual. Na espécie bufalina, a liberação do leite ocorre somente na presença do bezerro, ainda que os demais fatores possam contribuir para isso, de modo que o leite residual não representa um problema relevante.

Vários fatores têm levado a prejuízos na pecuária bovina leiteira, dentre eles: menor comprimento do duto papilar; densidade e composição lipídica na queratina, tônus do músculo esfíncter papilar, formato do óstio papilar; amamentação coletiva; manejo inadequado do rebanho, e injúrias promovidas durante a ordenha manual ou mecânica, (Seykora \& McDaniel 1985, Nicherson 1987, Shukla et al. 1997).

A relação do diâmetro papilar com o diâmetro do insuflador influencia diretamente a qualidade da ordenha, devido ao "colapso na linha de fluxo", quando a pressão aplicada na região distal da papila é máxima, provocando um estiramento ao longo de seu eixo maior (Schalm et al. 1971). Por outro lado, após a ejeção do leite, o relaxamento na parede do insuflador forma uma pressão negativa que propicia que o vácuo continue agindo, resultando em maior dilatação do conduto papilar e seu encurtamento, favorecendo a entrada de substâncias estranhas para o interior do sistema. Além disso, esses autores relatam que lesões no óstio papilar como hiperemia e hemorragia podem ocorrer na sobre-ordenha em função da extensão do vácuo da ordenhadeira para o interior da cisterna papilar.

Sendo assim, apesar de fêmeas bovinas e bufalinas partilharem semelhanças morfológicas, as diferenças entre as duas espécies devem ser consideradas nos processos de produção. Desta forma, os conhecimentos morfológicos são necessários ao desenvolvimento de tecnologias para melhor aproveitamento zootécnico de fêmeas bufalinas dotadas de aptidão leiteira.

\section{REFERÊNCIAS}

Akhtar N. \& Thakuria K.D.D. 1999. Teat measurements and their relation with milk yield in swamp Buffaloes. Indian Vet. J. 76:412-416.

Arnold J.P. \& Weber A.F. 1957. Teat surgery. Vet. Med. 52:417-25.

Bacha Jr W.J. \& Wood L.M. 1990. Color Atlas of Veterinary Histology. Lea and Febiger, Philadelphia, p.96-97.

Banks W.J. 1992. Histologia Veterinária Aplicada. 2 $2^{\underline{a}}$ ed. Manole, São Paulo, p.8-13. 
Behmer O.A., Tolosa E.M.C. \& Freitas-Neto A.G. 1976. Manual de Técnicas para Histologia Normal e Patológica. Universidade de São Paulo, São Paulo, p.116-117.

Bernabé J. \& Peeters G. 1980. Studies on the motility of smooth muscles of the teats in lactating cows. J. Dairy Res. 47:259-275.

Costa E.0. 1999. Controle e prevenção de mastite em bubalinos, p.68-83. In: Tonhati H., Barnabe V.H. \& Baruselli P.S. (ed.), Bubalinos: sanidade, reprodução e produção. Funep, Jaboticabal.

Didio L.J.A. 19552. Dados anatômicos sobre o "piloro" íleo-ceco-cólico (com observação in vivo da "papila" íleo-ceco-cólica). Revta Hosp. Nossa Senhora da Aparecida, São Paulo, 5(4):191-442.

Dyce K.M., Sack W.O. \& Wensing, C.J.G. 1990. Tratado de Anatomia Veterinária. Guanabara Koogan, Rio de Janeiro, p.477-482.

Jankus E.F. \& Baumann L.E. 1986. Blood flow to the distal part of the teat (mammary papilla) of lactating dairy cows. Am. J. Vet. Res. 47:283-285.

Junqueira L.C.V., Bignonas G. \& Bretan R.P. 1979. Picrosirius staining plus polarization microscopy, a specific method for collagen detection in the tissue sections. Histochem. J. 11:447-455.

Junqueira L.C. \& Carneiro J. 2004. Histologia Básica. 10ª ed. Guanabara Koogan, Rio de Janeiro. 488p.

Miglino M.A. 1999. Anatomy of the genital organs and placentons in buffaloes, p.119-121. In: Tonhati H., Barnabe V.H. \& Baruselli, P.S. (ed.), Bubalinos: sanidade, reprodução e produção. Funep, Jaboticabal.

Nicherson S.C. 1987. Resistance mechanisms of the bovine udder: New implications for mastitis control at the teat end. J. Am. Vet. Med. Assoc. 191:1484-1488.

Nicherson S.C., Pankey J.W. 1983. Citologic observation of the bovine teat end. Am. J. Vet. Res. 44:1433-1441.

Nickel R., Schummer A., Seiferle E. \& Sack W.O. 1981. The circulatory system, the skin, and the coetaneous organs of the domestic mammals, p.506511. In: Idem (ed.), The Anatomy of Domestic Animals. Verlag Paul Parey, Berlin.

Pounden W.D. \& Grossman J.D. 1950. Wall structure and closing mechanisms of the bovine teat. Am. J. Vet. Res. 11:349-354.

Rao A.V.N. \& Murthy T.S. 1991. Studies on morphological udder and characteristics of reverine Buffaloes in Andhra Pradesh. Buffalo Bulletin 10:18-22.

Rathore A.K. \& Sheldrake R.F. 1977. Teat orifice stretchability associated with teat diameter gradient and milk yield in lactating cows. Animal Prod. 24: 215-220.

Schalm O.W., Carrol E.J., Jain N.C. 1971. The mastitis complex: A brief summary, p.1-22. In: Idem (ed.), Bovine Mastitis. Lea and Febiger, Philadelphia.

Schalm O.W., Carrol E.J. \& Jain N.C. 1971. Origin, development and evolution of the mammary glands, p.23-35. In: Idem (ed.), Bovine Mastitis. Lea and Febiger, Philadelphia.

Schimit K.A, Arighi M. \& Dobson H. 1994. Postoperative evaluation of the surgical treatment of accessory teat and gland cistern complexes ìn dairy cows. Can. Vet. J. 34:25-30.

Seykora A.J. \& McDaniel B.T. 1985. Udder an teat morphology related to mastitis resistance: A review. J. Dairy Sci. 68:2087-2093.

Shukla S.K., Dixit V.P., Thapliyal D.C., Garg S.K. \& Kumar A. 1997. A note on the incidence of bovine mastitis in relation to teat shape size and quarters affected. Indian Vet. J. 74:989-990.

Steere J.H., Moody K.M. \& Healy J. 1960. Open teat sinus surgery for correcting teat occlusions. Part I. J. Am. Vet. Med. Assoc. 136:75-82.

Tomar S.S. \& Verma G.S. 1974. A note on the incidence of hypotelia in Buffalo. Indian Vet. J. 61:623-624.

Tonhati H. 1999. Resultados do controle leiteiro em bubalinos, p.90-109. In: Tonhati H., Barnabe V.H. \& Baruselli P.S. (ed.), Bubalinos: sanidade, reprodução e produção. Funep, Jaboticabal.

Uppal S.K., Singh K.B., Bansal B.K., Nauriyal D.C. \& Roy K.S. 1995. Histomorphological study on the teat (Mammary papilla) of Indian buffalo. Indian J. Anim. Sci. 65:853-856.

Vale W.G. 1999. Perspectivas da bubalinocultura no Brasil e na América Latina, p.1-26. In: Tonhati H., Barnabe V.H. \& Baruselli P.S. (ed.), Bubalinos: sanidade, reprodução e produção. Funep, Jaboticabal.

Verma G.S., Tomar S.S. \& Tomer O.S. 1984. Incidence of supernumerary teats (SNT) and their relationship with some economic traits in Murrah Buffaloes. Indian Vet. J. 61:521-522. 